\title{
Trends and correlates of sexually transmitted infections among sexually active Ugandan female youths: evidence from three demographic and health surveys, 2006-2016
}

\author{
Veronicah Masanja ${ }^{1}$, Solomon Tsebeni Wafula ${ }^{1,2^{*}}$ (D) Tonny Ssekamatte ${ }^{2}$, John Bosco Isunju²,
}

Richard K. Mugambe ${ }^{2}$ and Guido Van Hal ${ }^{1}$

\begin{abstract}
Background: Female adolescents and young women have the highest risk of curable sexually transmitted infections (STIS) globally. Data on the prevalence of STIs among young women in Uganda are limited. In this study, we investigated the time trends and correlates of STls among adolescent girls and young women (15-24years) in Uganda.

Methods: We estimated the percentage of women 15-24 years from three recent consecutive Uganda Demographic and Health Surveys (2006, 2011, and 2016), who reported suffering from genital sores, and or genital discharge or any other varginal complaints acquired after sexual intercourse within 12 months of the studies and examined the changes over time. A pooled multivariable logistic regression was used to examine the correlates of reporting an STI in the last 12 months preceding the study. Svyset command in Stata was used to cater for the survey sample design.
\end{abstract}

Results: The pooled self-reported STI prevalence was 26.0\%. Among these young women, 22.0, 36.3, and 23.1\% reported a sexually transmitted infection in 2006, 2011, and 2016 respectively. Between 2006 and 2011, there was evidence of change $(+14.3 \%, p<0.001)$ in STI prevalence before a significant reduction $(-12.0 \%, p<0.001)$ in 2016. Youths aged $20-$ 24 years reported a higher STI prevalence (27.3\%) compared to young participants (23.6\%). Correlates of reporting an STI among rural and urban young women were: having multiple total lifetime partners (adjusted odds ratio (aOR 1.6, 95\% Cl 1.4-1.6), being sexually active in the last 4 weeks (aOR 1.3, 95\% Cl 1.1-1.6), and being affiliated to Muslim faith (aOR 1.3, 95\% Cl 1.1-1.6) or other religions (aOR 1.8, 95\% Cl 1.1-2.9) as compared to Christian were more likely to report an STI. Living in Northern Uganda compared to living in Kampala city was found protective against STIS (aOR 0.5, 95\% Cl 0.3-0.7).

Conclusion: The prevalence of STIs was high among female youths, 15-24 years. This highlights the need for a comprehensive STIs screening, surveillance, and treatment programme to potentially reduce the burden of STIs in the country.

Keywords: Sexually transmitted infections, Female youths, Trends, Correlates, Uganda

\footnotetext{
* Correspondence: swafula@musph.ac.ug

'Department of Epidemiology and social medicine, Faculty of Medicine and

Health Sciences, University of Antwerp, Antwerp, Belgium

${ }^{2}$ Department of Disease Control and Environmental Health, Makerere

University, Kampala, Uganda
}

(c) The Author(s). 2021 Open Access This article is licensed under a Creative Commons Attribution 4.0 International License, which permits use, sharing, adaptation, distribution and reproduction in any medium or format, as long as you give appropriate credit to the original author(s) and the source, provide a link to the Creative Commons licence, and indicate if changes were made. The images or other third party material in this article are included in the article's Creative Commons licence, unless indicated otherwise in a credit line to the material. If material is not included in the article's Creative Commons licence and your intended use is not permitted by statutory regulation or exceeds the permitted use, you will need to obtain permission directly from the copyright holder. To view a copy of this licence, visit http://creativecommons.org/licenses/by/4.0/ The Creative Commons Public Domain Dedication waiver (http://creativecommons.org/publicdomain/zero/1.0/) applies to the data made available in this article, unless otherwise stated in a credit line to the data. 


\section{Background}

Globally, the burden of sexually transmitted infections (STIs) remains a high public health concern. It is estimated that more than 1 million curable STIs are acquired every day worldwide, and 376 million new cases occur each year [1]. The burden of STIs is disproportionately higher in low and middle-income (LMIC) settings where an estimated $75-85 \%$ of new cases occur globally [2, 3]. If left untreated, STIs can result in adverse sexual, reproductive, and maternal-child health consequences including infertility, increased HIV risk, pelvic inflammatory diseases, ectopic pregnancies, and perinatal transmissions among others [4-6].

Although STIs affect all age groups, adolescents and young people aged 15-24 years are particularly more vulnerable [7, 8]. A study across three primary African regions (Southern Africa, Southern/Eastern Africa community based and East Africa high risk) revealed that all STIs except herpes simplex virus 2 (HSV 2) were more prevalent among young women, 15-24 years compared to those aged 25-49-years regardless of population type or region [9].

In Uganda, the prevalence of self-reported STIs has remained persistently high, with an increase from $22 \%$ in 2006 to $27 \%$ in 2011 [10], while up to 1.5 million cases of STIs were reported between 2015 and 2017 [2, 11]. This high prevalence of STIs and associated adverse health outcomes makes STI control a public health priority. Notably, STIs increase the risk of HIV acquisition and are the leading cause of disability-adjusted life years (DALYs) among women of reproductive age $[4,12]$. Moreover, STIs acquired from regular partners account for up to $70 \%$ of the burden of female infertility [13]. Through several evidence-based strategies, such as ensuring community awareness on risks, prevention strategies, and treatment of STIs, this high burden of STIs and their effects are largely preventable $[2,4,14]$.

The major components of Uganda's current strategy on STI / HIV management include primary prevention strategies such as vaccination for Human papillomavirus and Hepatitis B, male circumcision, and behavioral change communication. Syndromic management, which involves the use of signs and symptoms rather than laboratory tests is also used to guide the treatment of STIs [15]. Despite these interventions, STIs are on an upward trend [8] and although the incidence is highest among young people, they have the least access to quality STI prevention and management services [9]. Management of STIs at public facilities where most youths seek these services is known to be poor, even when health workers are adequately trained and drugs and other consumables are adequately stocked and supplied [16]. The poor services are attributed to multiple barriers including the stigma associated with seeking STI services, confidentiality concerns, and method of specimen collection, conflicting school/work, and clinic schedules as well as the inability to pay for services $[3,17]$. Moreover, routine screening for asymptomatic infection is not performed [18] and a large number of people with STIs remain asymptomatic and therefore undiagnosed [12]. These asymptomatic cases are more frequent among youths especially young women compared to older people [19].

Some studies have been conducted on STIs in Uganda, but few of these studies have addressed the burden and their correlates among youths aged 15-24 years. Moreover, there is currently no study that has examined the prevalence of STIs among sexually young people using nationally representative data [20]. To understand the prevalence of STIs and their correlates among youths and inform public health planning and effective interventions, this study examined the trends and correlates of STIs among sexually active female youths aged 15-24 years who participated in 2006, 2011, and 2016 Uganda Demographic and Health Survey (UDHS).

\section{Methods \\ Study design and data sources}

This study utilized secondary data from the Uganda Demographic and Health Surveys (UDHS) round of 2006, 2011, and 2016. These are multi-stage nationally representative surveys of households conducted in Uganda every 5 years and collect information on population health along with the socioeconomic and demographic characteristics of respondents. All women aged 15-49 years in sampled households provide self-reported information in the individual woman's questionnaire about the different STIs they have been experienced within the last 12 months of the survey. The questions focused on whether the women had experienced any genital sores, genital discharge or both or other varginal complaints after sexual intercourse, during the study period. The data sets used did not include information on HIV, hence its exclusion from the self-reported STIs in this study. The analysis in this paper was based on the women's questionnaire and captured detailed information on respondents, socio-demographic characteristics, sexual behavior, wealth status, maternal and child health as well as different health outcomes including STIs in the last 12 months before each survey [15, 21, 22].

With permission obtained online, the UDHS datasets were downloaded from the DHS website https://www. dhsprogram.com. These surveys were conducted by the Uganda Bureau of Statistics (UBOS) in collaboration with the Ministry of Health $(\mathrm{MOH})$, with technical support and funding from the Government of Uganda, the United States Agency for International Development (USAID), the United Nations Children's Fund (UNICEF), and the United Nations Population Fund (UNFPA). 


\section{Study population}

The study population included sexually active female youths (adolescent girls and young women) aged 15-24 years. We included minors (participants aged between 15 and 17 years) but with consent from their parents or guardians. Respondents above aged 25 and above and those who were not sexually active were excluded.

\section{Study setting and sample size determination}

This was a nationally representative survey carried out in Uganda. Uganda has a projected population of 41.5 million people according to the 2016 population survey [15]. .For a representative sample, a two-stage cluster sampling method was used, using the Uganda National Population and Housing Census (NPHC) sampling frame, which is a complete list of all census enumeration areas (EAs). In Uganda, EAs is a geographic area covering an average of 10 households. At the time of the recent NPHC, Uganda was divided into 112 districts, which were further divided into 15 sub-regions for this survey. Randomly selected nationally representative samples of households were used in each of the surveys $[15,21,22]$. For analysis in this study, data on sexually active female youths aged 15-24years for the years 2006, 2011, and 2016 were extracted for analysis. The flow chart for selection of study population is highlighted in Fig. 1.

\section{Study variables}

We extracted data from the individual women's data set and particularly obtained information for women in the age category $15-24$ years at the time of each survey. Our main outcome was the "self-reported prevalence of STIs" within 12 months of the survey. A participant was considered to have had STIs if she reported one or more of the following syndromes: abnormal vaginal discharge, genital ulcer or sores, or any other complaints in the varginal area following sexual contact in the past 12 months before data collection. The definition excludes HIV and bacterial Vaginosis which are difficult to diagnose without laboratory tests. This was used to construct a binary outcome with values of 0 for "no" and 1 for "yes". The correlates of STIs examined in all the datasets included socio-demographic and sexual behavior characteristics. The sociodemographic factors included age (categorized as 15-19 and 20-24), type of place of residence (categorized as Rural or Urban), region, religion, marital status, and education, type of marriage, household wealth quintile, and spousal age. The level of education was recorded as no education, primary level, or secondary or higher level. Marital status was classified into married/living with a partner, not married or other, and type of marriage as polygamous or not. The regions were coded as Kampala, East, North, West, and Central, while religion as Christians, Muslims, and others, while wealth quintiles were grouped into poor, middle, and rich. Sexual behavior variables included age at first sexual intercourse which was grouped into $<15$ years, 15-19 years, and $20-24$ years, the number of sexual partners categorized into 1 or more, the total number of lifetime partners classified into 1 and 2 or more, recent sexual activity into "not active in last 4 weeks" or "active in the last 4 weeks", heard of STIs (yes or no) and condom use which was grouped into "yes" or "no". consistent condom use was defined as always using a condom at every sexual intercourse with every sexual partner.

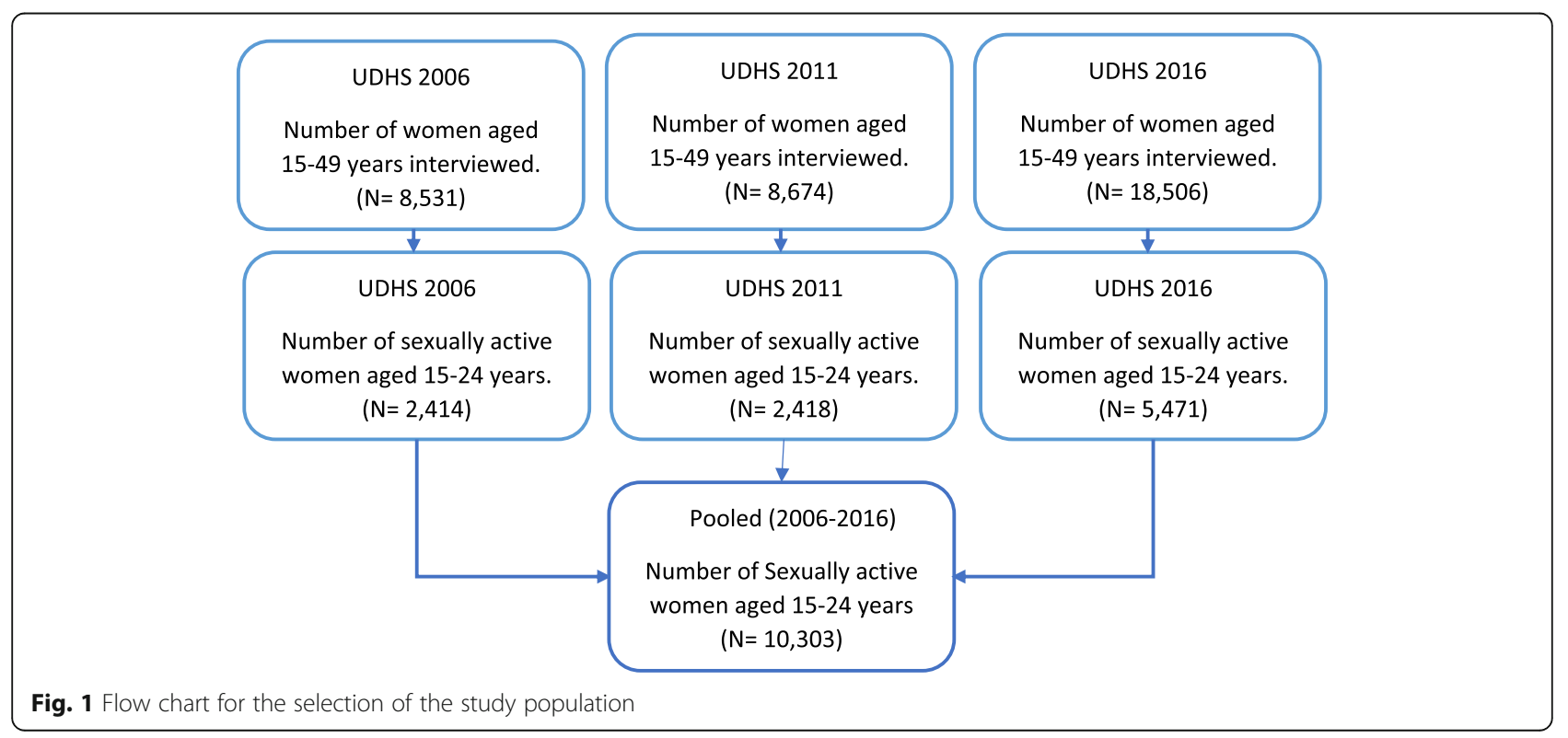




\section{Statistical analysis}

All statistical analyses were performed using STATA version 14.0 software. To ensure the representativeness of the population, we used the svyset command to match the multistage cluster sampling design method. In the svyset command, we specified the sample weights (to 6 decimal points) and then used cluster as the primary sampling unit and specified the strata (represented by different regions of Uganda). The different data sets were checked for completeness and consistency, cleaned, coded, and appended for pooled analysis $[15,21,22]$. The unit of analysis was the individual sexually active female youth aged 15-24 years. Descriptive analysis was performed to report frequencies and proportions of STIs for each survey year and generate frequency tabulations to show the trends of STIs and describe the covariate and their distributions over the three survey periods 2006, 2011, and 2016. Bivariate analysis was then conducted for each of the data sets separately using logistic regression to determine the association between the STI status and its correlates. All significant variables with $p<0.05$ at a $95 \%$ confidence interval for either of the data sets were selected for inclusion in the multivariate analysis. In the multivariate analysis, three models were fitted in steps to determine how they independently predicted STIs among the youths using the pooled dataset. Model I contained the year of the interview as the main correlate of STIs to determine its independent effect on the prevalence of self-reported STIs. In Model II, sexual behaviors were added to the first model, and in Model III, sociodemographic characteristics were added to produce the final adjusted model. This model included the correlates, adjusting for sexual behaviors, and sociodemographic characteristics. The pooled data were also used to analyze trends in the prevalence of STIs [23]. Adjusted odds ratios (aOR) and 95\% confidence intervals $(\mathrm{CI})$ were reported.

\section{Results}

\section{Distribution of socio-demographic characteristics}

We analyzed data for sexually active young women aged 15-24 years from all three surveys. The total sample size was 10,303 female youths: 2414 in 2016, 2418 in 2011, and 5471 in 2016 (Table 1). More than half (64\%) of the respondents were aged $20-24$ years and had a mean age of $20.4(\mathrm{SD}=0.03)$. Over $70 \%$ of the women in each survey were from rural residences $(80 \%$ in $2006,76.6 \%$ in 2011 , and $73.6 \%$ in 2016). The majority of respondents were Christians $8691(84.4 \%)$, were married or living with partner 6328 (61.4\%), and employed 7095(68.7\%). Regarding education, 3679 (35.7\%) had received secondary education or higher (Table 1).
Trends in sexual behaviours and STIs

Half of the respondents in all three separate and pooled datasets (50.1\% pooled, and 47.0, 47,8 and 52.5 in 2006, 2011, and 2016, respectively) reported more than one lifetime sexual partner, and only $10.43 \%$ used condoms consistently (always) with their most recent partner. Likewise, in the pooled data, more than half $(55.6 \%)$ of the respondents reported having been sexually active in the last 4 weeks before the interview, consistent with $56.7,54.5$, and 55.6\% reported in 2006, 2011, and 2016, respectively. The majority $(72.9 \%)$ of the sexually active female youths in the pooled dataset had their first sexual intercourse between the ages between 15 and 19. Approximately $71.0 \%, 68.1$, and 74.0 had their first sexual encounters in 2006, 2011, and 2016, respectively (Table 2).

\section{Trends in the weighed prevalence of STIs among female youths aged $15-24$ years old}

The weighted prevalence of the STIs showing their distribution by year, age group, and region and sexual behaviours are reported in Table 3 . The table shows a weighted pooled STI prevalence of 26, 95\%CI (24.827.1). Among the curable STIs assessed, a prevalence of 13.0, 95\%CI (12.2-13.9), and 13.3, 95\%CI (12.5-14.2) were reported for genital ulcers and genital discharge, respectively. As shown in Table 3 and Fig. 2, about $22.0 \%$, \% of youth women reported an STI in 2006. This increased to $36.3 \%$ in 2011 , before declining to and $23.1 \%$ reported a sexually transmitted infection in 2006, 2011, and 2016 respectively. Between 2006 and 2011, there was evidence of change $(+14.3 \%, p<0.001)$ in STI prevalence before a significant reduction $(-12.0 \%$, $p<0.001)$.

In general, the prevalence of STIs) among youths 2024 years (27.3, 95\%CI (25.9-28.8) was significantly higher than that for young adolescents, 23.6, 95\%CI (21.8-25.4). Additionally, youths in the central region, 32.3, 95\%CI (29.4-35.3), and Kampala 28.4, 95\%CI (24.4-32.7) reported a higher prevalence of STIs compared to other regions, while the northern region had the lowest prevalence of STIs 16.0, 95\%CI (14.2-17.8) (Fig. 3).

\section{Relationship between STIs and different correlates and among Ugandan female youths}

In the bivariate analysis, recent sexual activity in the last 4 weeks prior to the interview, lifetime number of marriages, and the total lifetime number of sex partners were significant in all surveys while age group, region, marital status, religion, education, age at 1st sex, and employment were significant in either one or two of the survey datasets. Condom use was not significant in the bivariate analysis across all datasets (Table 4). 
Table 1 Distribution of Selected Socio-demographic characteristics; pooled and by year of the survey

\begin{tabular}{|c|c|c|c|c|}
\hline \multirow[t]{2}{*}{ Demographic Characteristics } & \multicolumn{4}{|c|}{ Frequencies (Percentages) } \\
\hline & $2006(n=2414)$ & $2011(n=2418)$ & $2016(n=5471)$ & Pooled $(N=10,303)$ \\
\hline \multicolumn{5}{|l|}{ Age group } \\
\hline $15-19$ & $833(34.5)$ & $923(38.2)$ & 1948(35.6) & $3704(36.0)$ \\
\hline $20-24$ & $1581(65.5)$ & 1495(61.8) & $3523(64.4)$ & $6599(64.0)$ \\
\hline \multicolumn{5}{|l|}{ Marital status } \\
\hline Not married & $886(36.7)$ & $918(37.8)$ & 2176(39.8) & 3975(38.6) \\
\hline Married/livingtogether & $1528(63.3)$ & $1505(62.2)$ & $3294(60.2)$ & $6328(61.4)$ \\
\hline \multicolumn{5}{|l|}{ Residence } \\
\hline Urban & $482(20.0)$ & $565(23.4)$ & $1444(26.4)$ & $2491(24.2)$ \\
\hline Rural & 1932(80.0) & 1854(76.6) & 4026(73.6) & $7811(75.8)$ \\
\hline \multicolumn{5}{|l|}{ Region } \\
\hline Kampala & 263(10.9) & 291(12.0) & $312(5.7)$ & $865(8.4)$ \\
\hline Central & $467(19.3)$ & $507(21.0)$ & 1354(24.8) & 2328(22.6) \\
\hline East & $590(24.4)$ & $650(26.9)$ & $1543(28)$ & $2783(27.0)$ \\
\hline North & $477(19.7)$ & $410(17.0)$ & 1025(18.7) & 1912(18.6) \\
\hline West & $618(25.6)$ & $560(23.2)$ & $1237(22.6)$ & $2415(23.4)$ \\
\hline \multicolumn{5}{|l|}{ Religion } \\
\hline Christian & 2068(85.7) & 2035(84.2) & 4587(83.9) & $8691(84.4)$ \\
\hline Muslim & $308(12.8)$ & $360(14.9)$ & $826(15.1)$ & $1494(14.5)$ \\
\hline Other religions & $36(1.5)$ & $22.6(0.9)$ & $57(1.0)$ & $116(1.1)$ \\
\hline \multicolumn{5}{|l|}{ Education } \\
\hline No education & $229(9.5)$ & $110(4.5)$ & $157(2.9)$ & $496(4.8)$ \\
\hline Primary education & $1522(63.1)$ & 1457(60.2) & $3149(57.6)$ & $6127(59.5)$ \\
\hline Secondary education & $562(23.3)$ & $741(30.6)$ & $1766(32.3)$ & $3069(29.8)$ \\
\hline Higher & $101(4.2)$ & $111(4.6)$ & 398(7.3) & $610(5.9)$ \\
\hline \multicolumn{5}{|l|}{ Literacy } \\
\hline Cannot read at all & $814(33.7)$ & $684(28.3)$ & $1351(24.7)$ & $2850(27.7)$ \\
\hline Able to read & 1483(61.5) & 1695(70.1) & 4091(74.8) & $7269(70.6)$ \\
\hline Other (blind or visually impaired) & $116(4.8)$ & 39(1.6) & $27.8(0.5)$ & 183(1.8) \\
\hline \multicolumn{5}{|l|}{ Wealth index } \\
\hline Poor & $943(39.1)$ & $863(35.7)$ & 2101(38.4) & $3907(37.9)$ \\
\hline Middle & $398(16.5)$ & 463(19.2) & $924(16.9)$ & $1785(17.3)$ \\
\hline Rich & 1073(44.4) & 1092(45.1) & $2446(44.7)$ & $4610(44.7)$ \\
\hline \multicolumn{5}{|l|}{ Employment } \\
\hline No & $551(22.9)$ & $921(38.1)$ & $1724(31.5)$ & 3196(31.1) \\
\hline Yes & 1853(77.1) & $1496(61.9)$ & $3747(68.5)$ & 7095(68.9) \\
\hline
\end{tabular}

Source: Uganda Demographic Health and Health surveys (UDHS) 2006, 2011, 2016

In multivariable analysis, the year of the interview (2011), being sexually active in the last 4 weeks, having 2 or more lifetime sexual partners, being from the northern region of Uganda, and being affiliated with the Muslim faith and other religions were significantly associated with STI status among youths aged 15-24 years. Notably, in the year 2011, participants were more likely to report an STI across all models (OR: 1.9, 95\% CI
(1.5-2.3)) compared to 2011 and 2016, both had a similar but non-significant odds ratio. Compared with female youths who reported having one lifetime sexual partner, the odds of having an STI was higher among those who reported having 2 or more lifetime partners (OR:1.6, 95\%CI (1.4-1.9). Likewise, the odds of reporting an STI were slightly higher among female youths who were sexually active in the last 4 weeks prior to the respective 
Table 2 Trends in sexual behaviors and STls among Ugandan women age 15-24 years, UDHS 2006-2016

\begin{tabular}{|c|c|c|c|c|}
\hline \multirow[t]{2}{*}{ Characteristics } & \multicolumn{4}{|c|}{ Frequencies (Percentages) } \\
\hline & $2006(n=2414)$ & $2011(n=2418)$ & $2016(n=5471)$ & Pooled $(N=10,303)$ \\
\hline \multicolumn{5}{|l|}{ Age at first sex } \\
\hline$<15$ & $566(23.5)$ & $512(21.2)$ & $962(17.6)$ & 2040(19.8) \\
\hline $15-19$ & 1713(71.0) & $1644(68.1)$ & $4046(74.0)$ & 7402(71.9) \\
\hline $20-24$ & 134(5.6) & 259(10.7) & $460(8.4)$ & $854(8.3)$ \\
\hline \multicolumn{5}{|l|}{ Recent sexual activity } \\
\hline Not active & 1044(43.3) & 1098(45.5) & $2431(44.4)$ & 4573(44.4) \\
\hline Active in last 4 weeks & $1366(56.7)$ & $1318(54.5)$ & 3038(55.6) & 5722(55.6) \\
\hline \multicolumn{5}{|l|}{ Number of sex partners } \\
\hline Dont have & $280(11.6)$ & $319(13.2)$ & $603(11.0)$ & $1203(11.7)$ \\
\hline Only one & 2070(85.8) & $2021(83.7)$ & $4648(85.0)$ & 8739(84.8) \\
\hline 2 or more & $63(2.6)$ & $76(3.1)$ & $220(4.0)$ & $358(3.5)$ \\
\hline \multicolumn{5}{|c|}{ Total number of Lifetime partners } \\
\hline only one & $1276(53.0)$ & $1262(52.2)$ & $2598(47.5)$ & $5136(49.9)$ \\
\hline 2 or more & 1134(47.0) & 1155(47.8) & $2872(52.5)$ & $5161(50.1)$ \\
\hline \multicolumn{5}{|c|}{ Number of lifetime marriages/unions } \\
\hline Only one & 1593(90.0) & 1533(90.0) & $3470(90.8)$ & 6596(90.4) \\
\hline 2 or more & $177(10.0)$ & 171(10.0) & 350(9.2) & $698(9.6)$ \\
\hline \multicolumn{5}{|l|}{ Contraceptive knowledge } \\
\hline knows no method & $38(1.6)$ & $29(1.2)$ & $20(0.4)$ & $87(0.8)$ \\
\hline knows other method & $8(0.3)$ & $1(0.0)$ & $3(0.1)$ & $12(0.1)$ \\
\hline knows modern method & 2368(98.1) & 2389(98.8) & $5448(99.6)$ & $10,205(99.1)$ \\
\hline \multicolumn{5}{|l|}{ Consistent condom use } \\
\hline No & 2204(91.3) & 2158(89.2) & $4866(89.0)$ & $9228(89.6)$ \\
\hline Yes & $210(8.7)$ & $260(10.8)$ & $604(11.0)$ & 1074(10.4) \\
\hline \multicolumn{5}{|l|}{ Heard about STIs } \\
\hline No & $11(0.4)$ & $1(0.1)$ & $9(0.2)$ & $21(0.2)$ \\
\hline Yes & 2403(99.6) & 2416(99.9) & $5461(99.8)$ & $10,280(99.8)$ \\
\hline Do not know & & $1(0.1)$ & & $1(0.0)$ \\
\hline \multicolumn{5}{|l|}{ Had genital sore } \\
\hline No & 2072(86.1) & 2034(84.2) & 4844(88.6) & $8950(87.0)$ \\
\hline Yes & $336(13.9)$ & $381(15.8)$ & $625(11.4)$ & $1342(13.0)$ \\
\hline \multicolumn{5}{|l|}{ Had genital discharge } \\
\hline No & $2121(88.4)$ & 2079(86.2) & $4710(86.2)$ & $8911(86.7)$ \\
\hline Yes & 279(11.6) & $334(13.8)$ & 757(13.8) & $1370(13.3)$ \\
\hline \multicolumn{5}{|c|}{ Has had any STIs in the last 12 months } \\
\hline No & 1882(78.0) & $1541(63.7)$ & $4205(76.9)$ & $7628(74.0)$ \\
\hline Yes & $532(22.0)$ & $878(36.3)$ & $1265(23.1)$ & $2675(26.0)$ \\
\hline
\end{tabular}

Source: Uganda Demographic Health and Health surveys (UDHS) 2006, 2011, 2016

survey (OR:1.3, 95\% CI (1.1-1.6)). Besides the sexual behaviours, the youths affiliated with the Muslim faith (OR: 1.3, 95\% CI (1.1-1.6)) and other religions (OR: 1.8, 95\% CI (1.1-2.9) had higher odds of reporting an STI compared to those affiliated to Christianity. On the other hand, the northern region was found to be inversely associated with reporting any STI among female youths aged 15-24 years with youths from Northern Uganda having 0.5 times lower odds of reporting an STI compared to other regions (OR $0.5,95 \%(0.3-0.7)$. Although statistically significant $(p<0.05)$ in the different survey years in the bivariate analysis, marital status, age at first sex, age group, 
Table 3 Prevalence of sexually transmitted infections among female youths aged 15-24 years, UDHS 2006-2016

\begin{tabular}{|c|c|c|c|}
\hline \multirow[t]{2}{*}{ Characteristics } & \multicolumn{3}{|c|}{ Weighted Prevalences/percent $(95 \% \mathrm{Cl})$} \\
\hline & Any STI & Genital sores & Genital Discharge \\
\hline \multicolumn{4}{|l|}{ Year of interview } \\
\hline 2006 & $22.0(19.7-24.6)$ & 13.9(12.1-16.0) & 11.6(10.0-13.4) \\
\hline 2011 & 36.3(33.7-38.9) & 15.8(13.8-18.0) & $13.8(12.1-15.7)$ \\
\hline 2016 & $23.1(21.7-24.7)$ & $11.4(10.4-12.5)$ & 13.8(12.7-15.1) \\
\hline Pooled & $26.0(24.8-27.1)$ & $13.0(12.2-13.9)$ & $13.3(12.5-14.2)$ \\
\hline \multicolumn{4}{|l|}{ Age group } \\
\hline $15-19$ & $23.6(21.8-25.4)$ & 10.9(9.7-12.2) & 10.8(9.6-12.1) \\
\hline $20-24$ & $27.3(25.9-28.8)$ & $14.2(13.1-15.4)$ & 14.7(13.7-15.9) \\
\hline \multicolumn{4}{|l|}{ Region } \\
\hline Kampala & $28.4(24.4-32.7)$ & $15.1(12.0-18.8)$ & $16.8(14.2-19.7)$ \\
\hline Central & $32.3(29.4-35.3)$ & 16.4(14.4-18.8) & 18.3(16.3-20.4) \\
\hline East & $26.8(24.7-29.1)$ & $13.5(12.0-15.1)$ & 11.2(9.9-12.7) \\
\hline North & $16.0(14.2-17.8)$ & $7.2(6.0-8.5)$ & $7.9(6.7-9.4)$ \\
\hline West & $25.9(23.7-28.3)$ & 13.2(11.4-15.1) & $14.0(12.4-15.9)$ \\
\hline \multicolumn{4}{|l|}{ Residence } \\
\hline Urban & $26.8(24.5-29.3)$ & $12.5(10.9-14.4)$ & 16.4(14.4-18.6) \\
\hline Rural & $25.7(24.4-27.0)$ & $13.2(12.2-14.2)$ & $12.3(11.5-13.2)$ \\
\hline \multicolumn{4}{|l|}{ Marital status } \\
\hline Not married & $23.6(21.9-25.4)$ & 11.6(10.3-12.7) & 12.6(11.4-13.9) \\
\hline Married & $27.4(26.0-28.9)$ & 14.0(13.0-15.2) & 13.8(12.8-14.8) \\
\hline \multicolumn{4}{|c|}{ Total number of sexual partners } \\
\hline Only one & 19.5(18.2-20.9) & $9.6(8.6-10 . \wedge)$ & $9.0(8.2-10.0)$ \\
\hline 2 or more & $32.4(30.7-34.2)$ & $16.5(15.2-17.9)$ & 17.6(16.3-19.0) \\
\hline \multicolumn{4}{|l|}{ Recent sexual activity } \\
\hline Not active & $22.2(20.7-23.8)$ & 10.3(9.2-11.4) & 10.8(9.7-11.9) \\
\hline Active in the last 4 weeks & $28.9(27.4-30.5)$ & $15.3(14.2-16.5)$ & $15.3(14.2-16.5)$ \\
\hline \multicolumn{4}{|l|}{ Religion } \\
\hline Christian & $25.0(23.8-26.3)$ & $12.5(11.6-13.5)$ & $12.9(12.0-13.7)$ \\
\hline Muslim & $31.0(27.8-34.4)$ & 15.7(13.7-18.0) & $15.5(13.2-18.2)$ \\
\hline Other & $33.7(24.1-44.9)$ & $17.8(11.2-27.0)$ & $19.8(12.0-30.8)$ \\
\hline
\end{tabular}

Source: Uganda Demographic Health and Health surveys (UDHS) 2006,2011,2016

and having more than one lifetime partner, showed no statistical significance in the adjusted models (Table 5).

\section{Discussion}

In this study, we examined the trends in the prevalence and correlates of STIs among female youths aged 15-24 years in Uganda (2006-2016). Findings indicate that the overall prevalence was high (26.0\%); highest in 2011 and the lowest in 2006. Having 2 or more life partners, older age, sexual activity in the last 4 weeks, being a Muslim or belonging to other religions other than Christianity, were positively associated with reporting an STI while being from Northern Uganda was negatively associated with reporting any STI among the female youths aged $15-24$ years.

In this study, we found that the prevalence of STIs among youths was high, with the highest prevalence found among youths $20-24$ years old. This is consistent with several studies [24-28] showing that the prevalence of STIs was higher among young people aged 20-24 years compared to those 15-19 years. Surprisingly, the prevalence of STIs in 2011 was higher than in other years. There was a notable increase in prevalence between 2006 and 2011 and the decline later in 2016 . Considering the relationship between HIV and STIs, the high STI prevalence in 2011 may have been due to the 


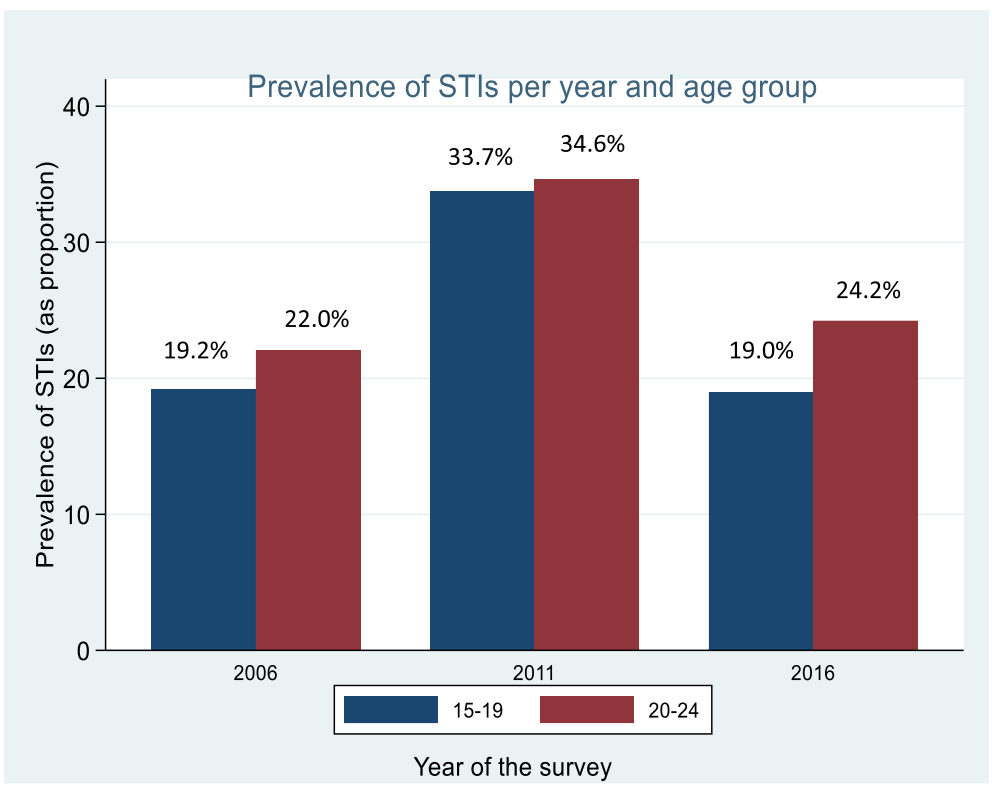

Fig. 2 Trends in prevalence of STIs among female youths aged 15-24 years by survey year and age group

higher HIV prevalence around 2011 [29]. It was also confirmed in a study in South Africa that HIV infection is a risk factor for STIs and likewise, STI infection is a risk factor for HIV acquisition [30, 31]. It is also probable that there was laxity in sexual and reproductive health service promotion programs but the decline in 2016 is probably due to increased uptake of sexual and reproductive health (SRH) among young people, leading to improved knowledge of HIV/STI, and promotion of safer sex following the SRH/HIV integration in Uganda in 2012 [32].
Both self-reported and laboratory-diagnosed STIs have been consistently high among young people with a history of having multiple lifetime partners, as seen in evidence from several studies over the years $[5,7,33$, 34]. The results from this study equally reveal that throughout all the survey years and in the pooled dataset, female youths aged 15-24 with a history of 2 or more lifetime sex partners reported higher cases of STIs than those who reported having only one sexual partner. This suggests that those with multiple partners may not be taking strict measures such as consistent condom use

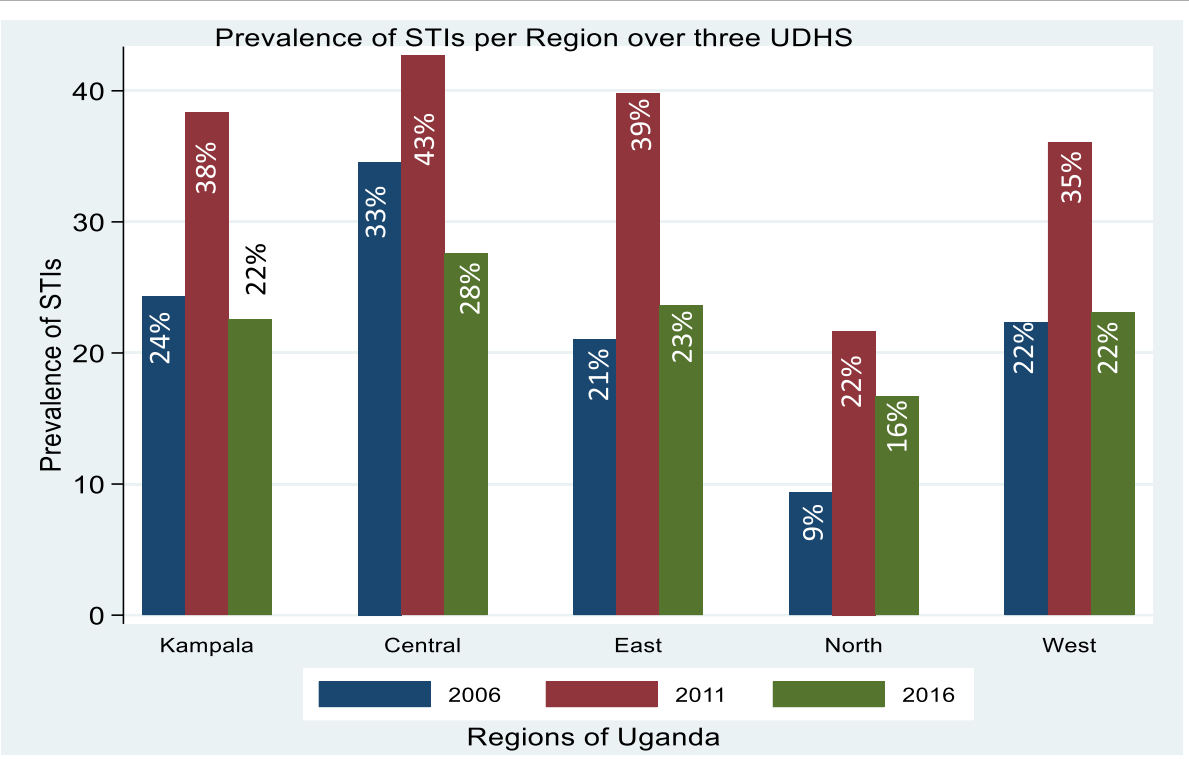

Fig. 3 Regional Trends in the Prevalence of STIs among female youths aged 15-24 years by survey year 
Table 4 Bivariate analysis showing Relationship between reporting of STIs and selected correlates

\begin{tabular}{|c|c|c|c|c|c|c|}
\hline \multirow[t]{2}{*}{ Variables } & \multicolumn{2}{|l|}{2006} & \multicolumn{2}{|l|}{2011} & \multicolumn{2}{|l|}{2016} \\
\hline & OR $(95 \% \mathrm{Cl})$ & $P$-value & OR $(95 \% \mathrm{Cl})$ & $P$-value & OR $(95 \% \mathrm{Cl})$ & $P$-value \\
\hline \multicolumn{7}{|l|}{ Age group } \\
\hline $15-19$ & 1 & & 1 & & 1 & \\
\hline $20-24$ & $1.2(1.0-1.5)$ & 0.104 & $1.0(0.8-1.3)$ & 0.847 & $1.4(1.2-1.7)$ & $<0.001$ \\
\hline \multicolumn{7}{|l|}{ Residence } \\
\hline Urban & 1 & & 1 & & 1 & \\
\hline Rural & $1.1(0.8-1.6)$ & 0.644 & $1.0(0.7-1.3)$ & 0.822 & $0.9(0.7-1.1)$ & 0.153 \\
\hline \multicolumn{7}{|l|}{ Region } \\
\hline Kampala & 1 & & 1 & & 1 & \\
\hline Central & $1.6(1.0-2.7)$ & 0.047 & $1.2(0.8-1.8)$ & 0.347 & $1.3(0.9-1.8)$ & 0.103 \\
\hline East & $0.8(0.5-1.4)$ & 0.457 & $1.1(0.7-1.5)$ & 0.744 & $1.1(0.8-1.4)$ & 0.698 \\
\hline North & $0.3(0.2-0.6)$ & $<0.001$ & $0.4(0.3-0.7)$ & 0.001 & $0.7(0.5-0.9)$ & 0.015 \\
\hline West & $0.9(0.5-1.5)$ & 0.680 & $0.9(0.6-1.3)$ & 0.604 & $1.0(0.8-1.4)$ & 0.843 \\
\hline \multicolumn{7}{|l|}{ Religion } \\
\hline Christian & 1 & & 1 & & 1 & \\
\hline Muslim & $1.8(1.3-2.5)$ & 0.001 & $1.4(1.1-1.9)$ & 0.013 & $1.2(0.9-1.5)$ & 0.203 \\
\hline Other & $2.3(0.9-5.6)$ & 0.069 & $1.4(0.6-3.2)$ & 0.413 & $1.3(0.6-2.7)$ & 0.462 \\
\hline \multicolumn{7}{|l|}{ Education } \\
\hline No education & 1 & & 1 & & 1 & \\
\hline Primary & $1.2(0.8-1.8)$ & 0.476 & $1.6(1.0-2.5)$ & 0.067 & $1.6(1.0-2.7)$ & 0.051 \\
\hline Secondary & $1.1(0.7-1.7)$ & 0.816 & $1.0(0.6-1.6)$ & 0.994 & $1.9(1.2-3.2)$ & 0.010 \\
\hline Higher & $0.9(0.5-1.7)$ & 0.695 & $1.1(0.5-2.3)$ & 0.802 & $1.3(0.7-2.2)$ & 0.450 \\
\hline \multicolumn{7}{|l|}{ Employment } \\
\hline No & 1 & & 1 & & 1 & \\
\hline Yes & $0.9(0.7-1.3)$ & 0.730 & $0.8(0.7-1.1)$ & 0.139 & $1.2(1.0-1.5)$ & 0.024 \\
\hline \multicolumn{7}{|l|}{ Marital Status } \\
\hline Not married & 1 & & 1 & & 1 & \\
\hline Married/living & $1.5(1.2-2.0)$ & $<0.001$ & $1.1(0.9-1.5)$ & 0.336 & $1.4(1.2-1.7)$ & 0.001 \\
\hline \multicolumn{7}{|l|}{ Age at 1 st sex } \\
\hline$<15$ & 1 & & 1 & & 1 & \\
\hline $15-19$ & $0.8(0.6-1.0)$ & 0.106 & $0.8(0.6-1.1)$ & 0.184 & $0.8(0.6-0.9)$ & 0.004 \\
\hline $20-24$ & $0.5(0.3-0.9)$ & 0.031 & $0.8(0.5-1.1)$ & 0.210 & $0.7(0.5-0.9)$ & 0.016 \\
\hline \multicolumn{7}{|c|}{ Recent sexual activity in the last 4 weeks } \\
\hline Not active & 1 & & 1 & & 1 & \\
\hline Active & $0.6(0.5-0.8)$ & $<0.001$ & $0.8(0.6-0.9)$ & 0.007 & $0.7(0.6-0.8)$ & $<0.001$ \\
\hline \multicolumn{7}{|c|}{ Lifetime number of marriages/unions } \\
\hline Once & 1 & & 1 & & 1 & \\
\hline$>$ once & $1.6(1.1-2.5)$ & 0.019 & $1.7(1.2-2.5)$ & 0.005 & $1.3(1.0-1.7)$ & 0.049 \\
\hline \multicolumn{7}{|c|}{ Total lifetime sexual partners } \\
\hline Only one & 1 & & 1 & & 1 & \\
\hline 2 or more & $2.5(2.0-3.2)$ & $<0.001$ & $1.9(1.6-2.4)$ & $<0.001$ & $1.9(1.6-2.2)$ & $<0.001$ \\
\hline \multicolumn{7}{|l|}{ Condom use } \\
\hline No & 1 & & 1 & & 1 & \\
\hline yes & $1.0(0.7-1.5)$ & 0.896 & $0.9(0.6-1.3)$ & 0.605 & $0.8(0.6-1.0)$ & 0.071 \\
\hline
\end{tabular}

Source: Uganda Demographic Health and Health surveys (UDHS) 2006, 2011, 2016 ref Reference 
Table 5 Logistic regression analysis showing the relationship between reporting of STIs and selected correlates of STIs among female youths aged 15-24 years in Uganda using pooled data (Model building)

\begin{tabular}{|c|c|c|c|c|c|c|}
\hline \multirow[t]{2}{*}{ Selected factors } & \multicolumn{2}{|l|}{ Model 1} & \multicolumn{2}{|l|}{ Model 2} & \multicolumn{2}{|c|}{ Model 3 (fully adjusted model) } \\
\hline & OR $(95 \% \mathrm{Cl})$ & $P$-value & OR $(95 \% \mathrm{Cl})$ & $P$-value & OR $(95 \% \mathrm{Cl})$ & $P$-value \\
\hline \multicolumn{7}{|l|}{ Year of interview } \\
\hline 2006 (ref) & 1.0 & & 1.0 & & 1.0 & \\
\hline 2011 & $2.0(1.7-2.4)$ & $<0.001$ & $1.9(1.5-2.3)$ & $<0.001$ & $1.9(1.5-2.3)$ & $<0.001$ \\
\hline 2016 & $1.1(0.9-1.3)$ & 0.462 & $1.0(0.9-1.2)$ & 0.791 & $1.0(0.8-1.2)$ & 0.836 \\
\hline \multicolumn{7}{|l|}{ Age at first sex } \\
\hline$<15$ (ref) & & & 1.0 & & 1.0 & \\
\hline $15-19$ & & & $0.9(0.8-1.0)$ & 0.153 & $1.0(0.8-1.2)$ & 0.739 \\
\hline $20-24$ & & & $0.9(0.7-1.2)$ & 0.585 & $1.1(0.8-1.4)$ & 0.731 \\
\hline \multicolumn{7}{|c|}{ Recent sexual activity in the last 4 weeks } \\
\hline Not active (ref) & & & 1.0 & & 1.0 & \\
\hline Active & & & $1.3(1.1-1.5)$ & $<0.001$ & $1.3(1.1-1.6)$ & 0.002 \\
\hline \multicolumn{7}{|c|}{ Lifetime Number of marriages/unions } \\
\hline Once (ref) & & & 1.0 & & 1.0 & \\
\hline more than once & & & $1.1(0.9-1.3)$ & 0.348 & $1.1(0.9-1.3)$ & 0.522 \\
\hline \multicolumn{7}{|c|}{ Total number of life partners } \\
\hline Only one (ref) & & & 1.0 & & 1.0 & \\
\hline 2 or more & & & $1.9(1.6-2.1)$ & $<0.001$ & $1.6(1.4-1.9)$ & $<0.001$ \\
\hline \multicolumn{7}{|l|}{ Residence } \\
\hline Urban (ref) & & & & & 1.0 & \\
\hline Rural & & & & & $1.0(0.8-1.2)$ & 0.644 \\
\hline \multicolumn{7}{|l|}{ Region } \\
\hline Kampala (ref) & & & & & 1.0 & \\
\hline Central & & & & & $1.2(0.9-1.7)$ & 0.246 \\
\hline East & & & & & $0.9(0.6-1.3)$ & 0.615 \\
\hline North & & & & & $0.5(0.3-0.7)$ & $<0.001$ \\
\hline West & & & & & $1.0(0.7-1.4)$ & 0.791 \\
\hline \multicolumn{7}{|l|}{ Age group } \\
\hline 15-19 (ref) & & & & & 1.0 & \\
\hline $20-24$ & & & & & $1.0(0.8-1.2)$ & 0.846 \\
\hline \multicolumn{7}{|l|}{ Education } \\
\hline No education (ref) & & & & & 1.0 & \\
\hline Primary & & & & & $1.2(0.9-1.6)$ & 0.168 \\
\hline Secondary & & & & & $0.9(0.7-1.3)$ & 0.697 \\
\hline Higher & & & & & $0.8(0.5-1.3)$ & 0.319 \\
\hline \multicolumn{7}{|l|}{ Marital status } \\
\hline Not married (ref) & & & & & 1.0 & \\
\hline Married & & & & & $0.9(0.7-1.1)$ & 0.175 \\
\hline \multicolumn{7}{|l|}{ Religion } \\
\hline Christian (ref) & & & & & 1.0 & \\
\hline Muslims & & & & & $1.3(1.1-1.6)$ & 0.009 \\
\hline Other & & & & & $1.8(1.1-2.9)$ & 0.031 \\
\hline
\end{tabular}

Source: Uganda Demographic Health and Health surveys (UDHS) 2006, 2011, 2016 ref Reference 
to protect themselves from STIs. A study using nested health and the demographic survey also corroborates our findings [24]. Having multiple sexual partners provides an opportunity for transmission of STIs [20,35]. Improving partner notification supports and practices may therefore be of paramount importance in miinmizing the risk of STIs/HIV.

In Uganda, a study using the 2016 UDHS data revealed that engagement in sexual activities in the last 1 month prior to the survey was significantly associated with self-reported STI status [2]. This corroborates findings from our analysis of the pooled dataset, including data from the 2006, 2011, and 2016 UDHS that show an association between recent sexual activity in the last 4 weeks and self-reported STI status. This is also consistent with a study by Lewis [36] that revealed an association between STIs with recent unprotected sex.

Apart from sexual behaviours, some sociodemographic characteristics including religion and region of residence were associated with STI status among female youths aged 15-24 years.: Findings from this study reveal that women reporting Muslim and other non-Christian religions had higher odds of STIs. This may be attributed to several factors, including the higher observed proportion of Muslim women reporting 2 or more lifetime sexual partners, compared with women who practice Christianity in our study $(p=0.049)$ and in previous studies [20]. Moreover, a DHS study in Ethiopia indicated that Muslim affiliation is associated with earlier engagement in sex among adolescents compared to orthodox Christians [37]. Strategies to minimize the risk of STIs may need to be culturally informed and adapted to reach young Muslim women and their partners.

In corroboration with other studies conducted in Uganda $[2,7,10]$, our study shows an inversely significant association between STI status and coming from the northern region of Uganda. The northern region is classified among the rural regions of Uganda, so our results are consistent with findings from other studies conducted in Uganda [38, 39], which revealed that living in rural regions, especially northern Uganda, was protective against STI acquisition. Misinde [7] in his study argues that the low prevalence of STIs in northern Uganda may be due to cultural reasons, including strong norms against sexual relationships for young women. On the other hand, youths in urban areas tend to be heterosexually active and this increases their chances of contracting STIs [20]. In Malawi, studies show that females from urban richer wealth quintiles were more likely to report multiple sexual partnerships which were found to be a risk factor for HIV and other STIs [20,40]. Its documented that some young females in this settings engage in transactional sex as a means of survival against poverty [20]. .This then exposes them to a high risk of STIs/HIV.

\section{Strengths and limitations of the study}

The main strength of this study is that it uses data from the Uganda demographic and health surveys, which are nationally representative studies and have large datasets that increase the power. Data from three different survey years were used for analysis, which allows for a better comparison of prevalence outcome variables and risk factors across the different years. The study however had its limitations; in this study, cross-sectional data were used, which may have introduced recall bias due to participants failing to remember certain exposures, or falsely recalling events influenced by having experienced the outcome and this may result in an underestimation of STIs prevalence. Additionally, the cross-sectional data used only show associations but not causation. Another limitation is that the outcome variable of self-reported STIs among female youths may introduce bias due to under-reporting of STIs hence resulting in low prevalence. Moreover, reporting of symptoms to determine STI status as used in this study is more likely to miss out on asymptomatic STI cases or those cases that would have been identified if participants had been diagnosed by the health worker. Despite these limitations, the results from this data provide insight into the prevalence and correlates of STIs among female youths aged 15-24 years in Uganda across the years. Finally, a complete case analysis of secondary data was used in this study, so we didn't have information and control over data quality. However, some variables in the data sets were already imputed, and the sample was large enough to provide enough power to answer the research question.

\section{Conclusion}

The prevalence of STIs was high among female youths aged 15-24 years old, with the highest prevalence registered in 2011 necessitating comprehensive STIs screening, surveillance, and treatment programme to minimize STIs burden in the country. The correlates of STIs among young female youths included the total number of lifetime partners, recent sexual activity, and affiliation to Islam while living in the northern region of Uganda were protective against STIs. Given that we found both sociodemographic and sexual behavioral predict STIs, there is a need to adopt a holistic approach towards diagnosis and management of STIs among youths in Uganda. For sexual behaviours, interventions should be targeted towards preventing engagement in multiple sexual relationships. On the other hand, different interventions should also be implemented based on regional STI trends for effectiveness.

\section{Abbreviations}

DHS: Demographic and Health Survey; MOH: Ministry of Health; SRH: Sexual and Reproductive Health; STI: Sexually Transmitted Infection; UNFPA: United Nations Population Fund; UNICEF: United Nations Children's Fund 


\section{Acknowledgements}

We wish to thank all the staff in the Department of Epidemiology and Social Medicine, Faculty of Medicine and Health Sciences, University of Antwerp, Belgium for their continued support during the entire study. We thank DHS program for availing data for this analysis.

\section{Authors' contributions}

VM and GVH conceived and designed the study. VM, STW, TS and JB analyzed the data. VM, JBI, RKM, and GVH wrote the first draft of the manuscript. GVH supervised and critiqued the first draft. All authors have reviewed and approved the final version of the manuscript for publication.

\section{Funding}

No funding was obtained for this study.

\section{Availability of data and materials}

The data used in this study are publicly available with permission from the Demographic and Health Survey Program on https://dhsprogram.com/data/ dataset_admin/index.cfm . The authors did not have any special privileges from MEASUREDHS/ICF International and therefore confirm that the data can be accessed by other researchers the same way as the authors did.

\section{Ethics approval and consent to participate}

This study used only secondary non-identifiable survey data which is publically available to registered users from the online data repositories. The procedures and questionnaires for DHS surveys have been reviewed and approved by the ICF International Institutional Review Board (IRB). The ICF International IRB ensures that the survey complies with the U.S. Department of Health and Human Services regulations for the protection of human subjects. Permission to use the data for this study was granted by the DHS Program. During data collection, written informed consent was obtained from adult respondents and for minors (participants below 18 years of age), written informed consent was first obtained from the parent or guardian followed by written assent by the actual participants.

\section{Consent for publication}

Not applicable.

\section{Competing interests}

The authors declare no conflicts of interest.

\section{Received: 16 July 2020 Accepted: 22 December 2020}

\section{Published online: 13 January 2021}

\section{References}

1. WHO. Sexually transmitted infections (STIs): Keyfacts; 2019. Available from: https://www.who.int/news-room/fact-sheets/detail/sexually-transmittedinfections-(stis).

2. Anguzu G, Flynn A, Musaazi J, Kasirye R, Atuhaire LK, Kiragga AN, et al. Relationship between socioeconomic status and risk of sexually transmitted infections in Uganda: multilevel analysis of a nationally representative survey. Int J STD AIDS. 2019;30(3):284-91.

3. WHO. Progress report on HIV, viral hepatitis and sexually transmitted infections, 2019. Accountability for the global health sector strategies, 2016 2021. Accountability for the global health sector strategies, 2016-2021. Geneva: World Health Organization; 2019

4. Culbreth R, Swahn MH, Salazar LF, Ametewee LA, Kasirye R. Risk factors associated with HIV, sexually transmitted infections (STI), and HIV/STI COinfection among youth living in the slums of Kampala, Uganda. AIDS Behav. 2020;24(4):1023-31.

5. Okoboi S, Castelnuovo B, Moore DM, Musaazi J, Kambugu A, Birungi J, et al. Incidence rate of sexually transmitted infections among HIV infected patients on long-term ART in an urban and a rural clinic in Uganda. BMC Public Health. 2019;19(1):87.

6. CDC. New CDC report: STDs continue to rise in the U.S. press release. Centre for disease control and prevention; 2019. Tuesday, October 8, 2019.

7. Misinde C, Nansubuga E, Nankinga O. Out of school female adolescent employment status and sexually transmitted infections (STIS) risk in Uganda: is it a plausible relationship? BMC Public Health. 2018;18(1):1173.

8. WHO. Report on global sexually transmitted infection surveillance, 2018. Geneva; 2018. 2018. Report No.: ISBN 978-92-4-156569-1.
9. Torrone EA, Morrison CS, Chen P-L, Kwok C, Francis SC, Hayes RJ, et al. Prevalence of sexually transmitted infections and bacterial vaginosis among women in sub-Saharan Africa: an individual participant data meta-analysis of 18 HIV prevention studies. PLoS Med. 2018;15(2):e1002511.

10. Nankinga O, Misinde C, Kwagala B. Gender relations, sexual behaviour, and risk of contracting sexually transmitted infections among women in union in Uganda. BMC Public Health. 2016;16:440.

11. MoH. District health information system (DHIS 2); 2018.

12. Katusiime C, Schlech WF, Parkes-Ratanshi R, Sempa J, Kambugu A. Characteristics of sexually transmitted infections among high-risk HIVpositive patients attending an Urban Clinic in Uganda. J Int Assoc Provid AIDS Care. 2016;15(1):36-41.

13. Ravi R, Nair SB. Correlates of sexually transmitted infections among women in southern India. Google Scholar. 2011;57(1):45-54.

14. Badawi MM, SalahEldin MA, Idris AB, Hasabo EA, Osman ZH, Osman WM. Knowledge gaps of STIs in Africa; Systematic review. PLoS One. 2019;14(9): e0213224.

15. UBOS ICF. Uganda demographic and health survey 2016. Kampala: UBOS and ICF; 2018

16. Harrison A, Wilkinson D, Lurie M, Connolly AM, Karim SA. Improving quality of sexually transmitted disease case management in rural South Africa. AIDS. 1998;12:17.

17. Braxton J, Davis DW, Emerson B, Flagg EW, Grey J, Grier L, et al. Sexually transmitted disease surveillance 2017; 2018.

18. Chirenje ZM, Gundacker HM, Richardson B, Rabe L, Gaffoor Z, Nair GL, et al. Risk factors for incidence of sexually transmitted infections among women in a human immunodeficiency virus chemoprevention trial: VOICE (MTN003). Sex Transm Dis. 2017:44(3):135-40.

19. Kaida A, Dietrich JJ, Laher F, Beksinska M, Jaggernath M, Bardsley M, et al. A high burden of asymptomatic genital tract infections undermines the syndromic management approach among adolescents and young adults in South Africa: implications for HIV prevention efforts. BMC Infect Dis. 2018; 18(1):499

20. Chialepeh WN, Sathiyasusuman A. Associated risk factors of STIs and multiple sexual relationships among youths in Malawi. PLoS One. 2015;10(8): e0134286.

21. UBOS ICF. Uganda demographic and health survey 2011. Kampala: UBOS and ICF International; 2012

22. UBOS. Uganda demographic and health survey 2006. Calverton: UBOS and Macro International; 2007.

23. Masibo PK, Makoka D. Trends and determinants of undernutrition among young Kenyan children: Kenya demographic and health survey; 1993, 1998, 2003 and 2008-2009. Public Health Nutr. 2012;15(9):1715-27.

24. Francis SC, Mthiyane TN, Baisley K, McHunu SL, Ferguson JB, Smit T, et al. Prevalence of sexually transmitted infections among young people in South Africa: a nested survey in a health and demographic surveillance site. PLoS Med. 2018;15(2):e1002512.

25. Jasumback CL, Perry SH, Ness TE, Matsenjwa M, Masangane ZT, Mavimbela $M$, et al. Point-of-care testing to guide treatment and estimate risk factors for sexually transmitted infections in adolescents and young people with human immunodeficiency virus in Eswatini. Open Forum Infect Dis. 2020; 7(3):ofaa052.

26. Riedner G, Dehne L, Karl. Sexually transmitted infections among adolescents: the need for adequate health services; 2005.

27. Nawagi F, Mpimbaza A, Mukisa J, Serwadda P, Kyalema S, Kizza D. Knowledge and practices related to sexually transmitted infections among women of reproductive age living in Katanga slum, Kampala, Uganda. Afr Health Sci. 2016;16(1):116-22.

28. Shannon CL, Klausner JD. The growing epidemic of sexually transmitted infections in adolescents: a neglected population. Curr Opin Pediatr. 2018; 30(1):137-43.

29. $\mathrm{MoH}$. The Uganda HIV and AIDS country Progress report. July 2015-June 2016; 2016

30. Zetola NM, Bernstein KT, Wong E, Louie B, Klausner JD. Exploring the relationship between sexually transmitted diseases and HIV acquisition by using different study designs. J Acquired Immune Def Syndromes (1999). 2009;50(5):546-51

31. Dionne-Odom J, Khan MJ, Jauk VC, Szychowski J, Long DM, Wallace S, et al. HIV status and other risk factors for prevalent and incident sexually transmitted infection during pregnancy (2000-2014). Infect Dis Obstet Gynecol. 2019;2019:6584101. 
32. MoH, UNFPA. National Dialogue on SRHR/HIV and SGBV integration report, 1st -2nd November; 2017.

33. Sabri B, Wirtz AL, Ssekasanvu J, Nonyane BAS, Nalugoda F, Kagaayi J, et al. Intimate partner violence, HIV and sexually transmitted infections in fishing, trading and agrarian communities in Rakai, Uganda. BMC Public Health. 2019;19(1):594.

34. Sentís A, Martin-Sanchez M, Arando M, Vall M, Barbera MJ, Ocaña I, et al. Sexually transmitted infections in young people and factors associated with HIV coinfection: an observational study in a large city. BMJ Open. 2019;9(5): e027245.

35. Ssekamatte T, Tetui M, Kibira SPS, Isunju JB, Mugambe RK, Nabiwemba E, et al. Multiple sexual partnerships and associated factors among young psychoactive-substance-users in informal settlements in Kampala, Uganda. PLoS One. 2020;15(10):e0239323.

36. Lewis FM, Bernstein KT, Aral SO. Vaginal microbiome and its relationship to behavior, sexual health, and sexually transmitted diseases. Obstet Gynecol. 2017;129(4):643-54.

37. Turi E, Merga BT, Fekadu G, Abajobir AA. Why too soon? Early initiation of sexual intercourse among adolescent females in Ethiopia: evidence from 2016 Ethiopian demographic and health survey. Int J Women's Health. 2020; 12:269-75.

38. Palomino González R, Kadengye DT, Mayega RW. The knowledge-riskbehaviour continuum among young Ugandans: what it tells us about SRH/ HIV integration. BMC Public Health. 2019;19(Suppl 1):604

39. Patra S. Socio-cultural correlates and risky sexual behaviour influencing prevalence of HIV/AIDS and STIs in Uganda: a gender perspective. Cogent Soc Sci. 2016;2(1):1166472.

40. Durevall D, Lindskog A. Economic inequality and HIV in Malawi. World Dev. 2012;40(7):1435-51.

\section{Publisher's Note}

Springer Nature remains neutral with regard to jurisdictional claims in published maps and institutional affiliations.

Ready to submit your research? Choose BMC and benefit from:

- fast, convenient online submission

- thorough peer review by experienced researchers in your field

- rapid publication on acceptance

- support for research data, including large and complex data types

- gold Open Access which fosters wider collaboration and increased citations

- maximum visibility for your research: over $100 \mathrm{M}$ website views per year

At BMC, research is always in progress.

Learn more biomedcentral.com/submissions 